\title{
Primary Commodity Export and Economic Growth in Sub Sahara Africa: Evidence from Panel Data Analysis
}

\author{
Matthew Kofi Ocran \\ Ghana Institute of Management and Public Administration (GIMPA) and \\ the Department of Economics, University of Fort Hare \\ Nicholas Biekpe \\ University of Stellenbosch Business School
}

\begin{abstract}
The paper sought to examine the impact of instability in primary commodity export earnings and the level of commodity dependence on economic growth in Sub Saharan Africa (SSA). Fixed effects panel data estimator was used in the empirical estimation. The findings of the study suggest that there is a negative relationship between instability in export earnings and economic growth. The results also indicate that the level of commodity dependence matter in determining economic growth in the region. The results of the paper have economic development policy implications for SSA economies and these are not farfetched. First, it appears the difficult growth experience of SSA is not solely due to instability in export receipts. The question of continued dependence on a narrow range of primary commodities is also matter of great importance.

Key words: Primary commodities dependence, export instability, economic growth, panel data analysis, Sub Saharan Africa.
\end{abstract}

JEL O13, O55, C33

\section{1}

\section{Introduction}

The role of primary commodities in economic performance in Sub Saharan Africa (SSA) is amply demonstrated by the high proportion of Gross Domestic Product (GDP) accounted for by the agricultural sector in most countries in the region. More vividly, primary commodity export dependence is illustrated by proportions of foreign exchange earnings that come from primary commodity exports. Average annual earnings over the period 1990-1999 from each country's three major primary commodities, varied from a low of 4 per cent (Djibouti) to a high of 95 per cent (Botswana). Thus with the exception of South Africa only four countries had less than 10 per cent of their earnings from the three leading exports (UNCTAD, 2004). More than half (52 per cent) of the 48 countries that constitute SSA obtain more than 60 per cent of their export earnings from only three commodities. Another 31 per cent also derived between 30-59 per cent from their three leading primary commodities. The four major non-oil commodities have been identified as cocoa, cotton, tea and coffee. For instance, the impact of decline in the price of cotton is usually most severe in Burkina Faso, Mali, Benin and Togo where cotton exports average 5-8 percent of GDP (IMF, 2005).

Given that countries in the region import almost all their technology as well as capital goods for both infrastructure development and production processes the importance of foreign exchange earnings cannot be overemphasized. For instance export revenues are a major determinant of balance of payment positions in these countries, external indebtedness ${ }^{1}$, fiscal balance, savings and investment levels. Therefore, changes in export earning instability and the extent of commodity dependence are expected to have some significant impact on 
economic growth outcomes. The question that comes to mind after considering the above issues is as follows; to what extent does commodity export revenue instability determine economic growth in SSA. The purpose of this paper is therefore to ascertain whether instability in commodity export earnings has an effect on economic growth. The other related objective is to examine the extent to which commodity dependence determines economic growth.

Despite the possible crucial role of commodities markets in economic development of the continent there is a severe dearth of comprehensive studies on the impact of commodities markets on economic development in Africa. The handful of studies that consider commodities markets in Africa dwell rather on assessing the impact of domestic market reforms for individual commodity markets (See Baffes, 2001; Larson, 1998; Varangis \& Schreiber, 2000; Jurajda \& Mitchell, 2001; Badienne et al., 2002). Others have also mostly reviewed the various stabilisation schemes and their effectiveness (Akiyama et al., 2003; Kruger, Schiff \& Valdes, 1991 and Mundlak, Cavallo \& Domenech, 1993). Though a few studies have looked at export instability and economic growth, these were conducted for regions of the developing world other than SSA except Gyimah-Brempong (1991). The present study thus attempts to address the perceived weaknesses in the aforementioned papers and to contribute to the understanding of the relationship between primary commodity export and long-term economic growth in SSA.

The structure of the paper is as follows, Section 2, presents a brief overview of previous studies on the role of commodities in economic growth while Section 3 discusses the research approach adopted for the empirical analysis. The result of the study is the subject of Section 4. Conclusions and policy implications arising out of the work are given in Section 5.

\section{2}

\section{Review of previous studies}

Empirical efforts aimed at estimating the longrun economic relationship between export instability and economic growth has generated conflicting results. While a number of studies find a negative relationship between export instability and economic growth others indicate a positive relationship. Yet another set of empirical studies concludes that the relationship between export instability and economic development in the long run is statistically insignificant.

The school of thought that finds a positive relationship asserts that in periods of export instability least developed countries (LDCs) respond to the volatility by adjusting and reducing consumption accordingly. It is further argued that as economies reduce consumption, savings and investment are increased with a resultant increase in economic growth. This approach implicitly assumes risk-aversion behaviour in the analytical framework (MacBean, 1966; Knudsen \& Parnes, 1975; Lam, 1980 and Savvides, 1984).

MacBean (1966) was one of the early economists who studied export instability and economic growth; he sought to ascertain empirically the widely held view that export fluctuations in developing countries were detrimental to economic performance. MacBean's book looked at the statistical and analytical dimension of the issues concerning stabilisation policies at the time. The book also looked at both the shortand long-run effects of exports instability on economic growth. Maizel (1968) in a review of MacBean's book concluded that the policy implications of the study were doubtful because the data series on developing countries in the sample of countries was inordinately short and defective. The articles that found a negative relationship between export instability and economic growth point out that the negative effect that instability in exports has on output, was through the creation of uncertainty in longterm planning coupled with imported input shortages (See Adams, Behrman \& Roldan, 1979; Glazekos, 1984; Kennen and Voivodas, 1972; Priovolus, 1981 and Gyimah-Brempong, 1991; Ozler \& Harrigan, 1988).

The methodology used by the "negative relationship" school of thought estimates regressions of GDP growth as dependent variable and an instability variable as independent. Again like the "positive relationship" group they all 
used cross-section data. Gyimah-Brempong (1991) with the aid of cross-section data on 34 SSA countries used the average data for the period 1960-86. Lastly, economists who took the position that export instability had no significant impact on economic growth in LDCs were of the persuasion that LDCs were able to foresee export instability (see Obidegwu \& Nziramasanga, 1981; Yotopoulus \& Nugent, 1977). They argue further that individual countries are then in position to put measures in place to assuage the impact of instability hence economic growth was largely unaffected.

As can be noticed all the studies reviewed used cross-section data. Furthermore the studies tended to lump all exports together. However, Mullor-Sebastian (1988) used a new approach where the data was disaggregated based on the level of development of a given sample country and the characteristics of the product exported. Mullor-Sebastian's argument was that the studies that lumped all exports together were flawed because of the reasons enumerated above. The paper therefore considers only two products: synthetic and natural fibre for developed and developing countries respectively.

Almost all the studies mentioned above considered LDCs as a group and as such the results generated by those studies may not necessarily be applicable to the SSA situation. For instance most of the studies considered exports in general and these often included manufactured as well as primary commodities. Sinha (1999) estimated the long-run relationship between export instability, investment and economic growth in some Asian countries. The paper departed from the old tradition of using cross-section data. Sinha (1999) rather used time series data like Love (1992) and Wilson (1994). Even though Sinha (1999) was a marked improvement on the previous studies his study looked at countries that included the likes of Japan and Indonesia. Thus the results cannot be applied to Sub-Saharan African countries.

\section{3}

\section{Methodology}

We extend the theoretical framework developed by Kruger et al. (1991) and Feder (1983). Exports are well thought-out as one of the inputs in the production function for SSA. We augment this with an exports revenue instability measure. The perception here is that, fluctuations in export earnings are likely to impact economic growth since almost all SSA countries rely on export proceeds to finance the bulk of their capital goods. Consequently a continued technical progress in these countries will depend on sustained ability to import needed technologies. However, the ability to sustain continued access to improved technologies depends on stable export earnings. Economic growth in the region's economies can be linked to the ability to import technologies at the right time during the production process. Again, since domestic markets are quite small, in order to specialise and harness the inherent advantages of economies of scale, exporting of primary commodities cannot be compromised. Lastly, export taxes have been reckoned to account for a large part of government revenues in SSA (see Ocran, 2005) development in infrastructure and other programmes are financed largely by export taxes, therefore improved increased exports will have a positive impact on economic growth.

The low financial sector development in SSA, which accounts for the poor state of capital mobility in the region also means that export revenue fluctuations cannot be smoothed out with inward capital flows. The above set of reasons jointly underscores the role of export earnings in the production of goods and services in SSA economies. In the light of the above theoretical and empirical reasons, we formally write the economic growth function for the study as follows;

$y=f(l, k, x, \tau)$

Where, $y$ is growth rate of output (GDP) and $l, k, x$ and $\tau$ are changes in labor force, gross capital stock, exports and instability in exports. The corresponding a priori expectations about the signs of the arguments of the function are positive for all except that of instability which cannot be determined a priori. In estimating equation (1) we are required to motivate the selected functional form. However, economic growth theory does not provide any leads 
in this direction. Hence we follow earlier papers (Feder, 1980 and Lam, 1980) that estimated growth equations for LDCs and other developing countries using linear specifications of the growth models.

\subsection{Estimation technique}

Unlike the previous studies that used crosssectional data we use a panel data analytical tool. The selected data structure affords us the opportunity to exploit both the time series nature and cross-sectional properties of exports instability and economic growth. And more importantly the data structure allows greater flexibility in modeling differences in behavior across countries in the region. We therefore use a panel data set of the form;

$y_{i, t}=x_{i, t}^{\prime} \gamma+\lambda_{t}+\eta_{i}+v_{i, t}$

$t=1, \ldots \ldots . T ; i=1, \ldots \ldots \ldots . N$

Where, $y$ is the changes in real GDP, $x$ represents the set of explanatory variables that explains variation in GDP. It includes an export instability measure, value of commodities exports, labour and stock of capital. The $\lambda_{t}$ and $\eta_{i}$ are time and individual specific effects while $x_{i, t}^{\prime}$ is a $k$ vector of explanatory variables. The total number of observations is $N T$. Some of the time invariant country effects considered in the modelling exercise is the degree of commodity dependence.

There are three ways of dealing with panel data estimation. The estimation methods are pooled cross-section, random effects and fixed effects estimation models respectively. Pooled cross-sectional models assume that there are no distinctions between the observations in terms of time and space. Thus country and time effects are assumed away. The literature on panel data estimation argues that pooled cross-section data do not control for "fixed unobserved differences" between the observations. This may lead to the emergence of individual intercepts for the various countries in panel estimation. The omission of fixed effects in pooled cross-section may risk omitted variable bias. Another consequence of pooling is that the disturbance terms may be correlated with groups. The random effects model is an attempt to improve on some of the shortcomings of pooled data by controlling for the correlation among the disturbances. However, like pooled cross-section estimators random effects also risk omitted variable bias. For instance if the country effects are correlated with other independent variables, the estimates of the coefficients of the regressors are biased (Green et al., 2001). The fixed effects model implicitly introduces dummy variables to account for all the country individual effects, therefore allowing for varying individual intercepts. The fixed effects estimator produces consistent estimations even if country specific disturbances are correlated with the regressors. Consequently, random effects models are seen as a mid-point on a continuum from pooled cross-section and fixed effects estimators.

Fixed effects estimators are rather less efficient since the approach requires the inclusion of dummies to account for individual country effects. On the other hand, random effects make use of simple variance estimates thus making it an efficient estimator. In the light of the merits and demerits of the various panel estimators the empirical question here is how does one decide on the most appropriate estimator for a given study?

\subsection{Choosing between random effects and fixed effects estimators}

The literature argues that for randomised experiments where one is confident that the regressors are independent of the omitted fixed effects, then the Breusch-Pagan test is the most appropriate test (Green, 2003). The test compares pooled cross-section estimators with the random effects estimators. Since the sample of countries in the present paper is not drawn based on a randomised experimental procedure, the more useful application would be the Hausman's specification test (Hausman, 1978). The test compares two estimators which are deemed consistent under the null hypothesis that there is no correlation between individual effects and the regressors. Both random and fixed effects estimators are consistent but the random effects is efficient, while the fixed effects is not. To the contrary, the alternate hypothesis states that individual effects are 
correlated with the regressors. While the random effects estimator is not consistent, the fixed effects estimator is consistent and efficient. As demonstrated in Green et al. (2001) if $\theta^{\text {eff }}$ stands for an estimator that is asymptotically efficient under a null hypothesis but consistent when the null hypothesis is false and $\theta^{\text {cons }}$ represents an estimator that is inefficient under the null but remains consistent under the alternate hypothesis, Hausman (1978) suggests that a chisquare test statistic can be formulated as;

$\chi^{2}[k]=\left(\theta^{\text {cons }}-\theta^{\text {eff }}\right)^{\prime}\left[\operatorname{var}\left(\theta^{\text {cons }}\right)-\operatorname{var}\left(\theta^{e f f}\right)\right]^{-1}\left(\theta^{\text {cons }}\right.$ $\left.-\theta^{\text {eff }}\right)$

Where, the degree of freedom $k$ is the same as the dimension of the vector $\theta$. The perception here is that if the null hypothesis is true, the difference between the two estimators, $\theta^{\text {cons }}-\theta^{\text {eff }}$, must be asymptotically small given that they are both consistent under the appropriate weight matrix, the quadrant form in the difference has an asymptotic chi-square distribution. The burden of proof is deemed to rest on the fixed effects model, if the null cannot be rejected the random effects regression stands.

\subsection{Data issues}

A sample of 31 SSA countries was selected for the study, the 17 other countries in the region were dropped mostly due to lack of data. However, South Africa was not picked because in most instances the figures for the country constituted an outlier because of her relatively big economy compared to the rest of the region. The data covered the decade, 1996-2005. The data was used to construct a balanced panel of 310 observations with each of the 31 countries having 10 observations each.

Economic output measured as GDP in constant 2000 US dollars was considered as the dependent variable. Gross capital stock (in constant 2000 US dollars), export earnings (in constant 2000 US dollars) and labour force constituted the regressors. The other regressors were a measure of export receipt instability and dummies representing, high, medium and low commodity dependence respectively. Countries that obtained more than 70 per cent of their export earnings from just 3 primary commodities were designated as high commodity dependent economies, those that received between 31 per cent and 69 per cent from commodity exports were described as medium commodity dependent while those receiving less than 30 per cent from commodity exports were designated as low commodity dependent countries. The value of exports was assumed to be equal to earnings from primary commodity exports for lack of data on primary commodity exports. In any case as indicated in UNCTAD (2004) the share of manufactured goods in merchandise trade is very low in the region.

The literature indicates an absence of a welldefined measure of export revenue instability (Gyimah-Brempong, 1991). In the present study however, we used the Holdrick-Prescott Filter in the construction of the export instability index. First, we decompose the export series into its trend and cyclical components respectively. We then employ normalised deviations from the trend as a measure of instability. All the data used in the construction of the dependent and independent variables were obtained from the World Development Indicators, WDI (World Bank, 2007).

\section{4}

\section{Discussion of empirical results}

This section of the paper presents findings of the descriptive analysis involving the variables used in the empirical estimation and the regression analysis.

\subsection{Summary statistics}

Before considering the regression results we discuss some descriptive statistics for the panel data set. Table 1 shows average performance across the 31 countries on four of the variables considered in the study. A cursory look at the explanatory variables indicates wide swings in all the variables except changes in the labour force which appear to have been modest. The variables are, earnings from primary commodity exports (exports), gross capital stock (capital), labour force (labour) and output (GDP). Over the decade 1996-2005 growth in export receipts varied between -13 per cent to a high of 37 
per cent annually. The figure compares well with growth in gross capital formation which also ranged from -20 per cent and 35 per cent. Growth in GDP on the contrary, varied between -2 per cent and 8 per cent but averaged 4 per cent per year across the region. The high standard deviation recorded in changes in export earnings underscores the problem of instability in export earnings; this instability is also reflected in gross capital stock (see Table 1).

\section{Table 1}

Growth rates (overall sample), 1996 - 2005

\begin{tabular}{|l|c|c|c|c|}
\hline Variable & Minimum & Maximum & Mean & $\begin{array}{c}\text { Standard } \\
\text { deviation }\end{array}$ \\
\hline Exports (constant 2000 US\$) & $-13 \%$ & $37 \%$ & $8 \%$ & 0.16 \\
\hline GDP (constant 2000 US\$) & $-2 \%$ & $8 \%$ & $4 \%$ & 0.03 \\
\hline Labour force & $1 \%$ & $4 \%$ & $2 \%$ & 0.01 \\
\hline Capital formation (constant 2000 US\$) & $-20 \%$ & $35 \%$ & $6 \%$ & 0.18 \\
\hline
\end{tabular}

Table 2

Measure of primary commodity diversification

\begin{tabular}{|l|l|l|}
\hline $\begin{array}{l}\text { High commodity } \\
\text { concentration }\end{array}$ & $\begin{array}{l}\text { Medium commodity } \\
\text { concentration }\end{array}$ & $\begin{array}{l}\text { Low commodity } \\
\text { concentration }^{3}\end{array}$ \\
\hline Botswana & Mali & Mauritius \\
Burundi & Cote d'Ivoire & Swaziland \\
Cameroon & Madagascar & Lesotho \\
Comoros & Senegal & \\
Chad & Burkina Faso & \\
Congo, Rep. & Zimbabwe & \\
Eritrea & Gambia & \\
Ethiopia & Benin & \\
Gabon & Sudan & \\
Ghana & Mozambique & \\
Guinea & Tanzania & \\
Guinea Bissau & & \\
Malawi & & \\
Rwanda & & \\
Togo & & \\
Uganda & & \\
Zambia & & \\
\hline
\end{tabular}

1 Countries that obtained 70 per cent or more of their export receipts from 3 primary commodities

2 Countries receiving between 30-69 per cent of their of their export receipts from 3 primary commodities

3 Countries that derive 30 per cent or less of their export earnings from primary commodity exports 
On the issue of commodity dependence only three countries in the 31 country sample under discussion are described as low commodity dependent economies. The majority of the countries on the other hand are high commodity dependent economies (see Table 2). The extent of primary commodity dependence or concentration was defined using the proportion of export earnings obtained from a given country's three top primary commodity exports over the period 1990-1999 (UNCTAD, 2003). Most of the countries in SSA can be described as high commodity dependent economies because the bulk of their earnings are obtained from commodity trade. Only a few countries in the selected sample depend on three commodities for 30 per cent or less of their earnings from primary commodity trade (see Table 2), these countries include Mauritius, Swaziland and Lesotho.

\subsection{Regression analysis}

Following the discussions on the selection of the appropriate panel data estimator we undertook a specification test to help determine the most suitable estimator. The resulting Hausman specification chi-square statistic $\left(\chi_{5}^{2}\right)$ of 23.58 indicates a rejection of the null that the difference in coefficients is not systematic. Consequently, the fixed effects model generalised least square (GLS) model is chosen as the appropriate estimator (See Table 3).

The outcome of the empirical estimation shows a negative relationship between instability in export receipts and economic growth in Sub Saharan African countries. The finding is largely consistent with the result obtained by Adams et al. (1979); Ozler and Harrigan (1988) and Gyimah-Brempong, (1991) among others, though different estimation techniques were used by the authors. The negative association between instability in export receipts and economic growth may be attributed to the creation of increased uncertainty in long-term fiscal planning and possibly imported input shortages. Given that capital expenditure is largely financed with earnings from exports due to low foreign direct investments and less developed capital markets, the importance of receipts from primary commodity exports is extremely important. This assertion is underscored by the very high coefficient associated with the capital stock regressor in the estimated regression.

Table 3

Comparison of panel data estimators: Dependent variable, output (GDP growth)

\begin{tabular}{|c|c|c|c|c|}
\hline Variable & $\begin{array}{l}\text { Fixed effects } \\
\text { coefficients }\end{array}$ & $\begin{array}{c}\text { Random effects } \\
\text { coefficients }\end{array}$ & Var (Diff.) & Probability \\
\hline Capital & $\begin{array}{c}1.2884 \\
(2.32)^{* *}\end{array}$ & 1.347575 & 0.000324 & 0.0010 \\
\hline Labour force & $\begin{array}{c}0.3314 \\
(15.82)^{* *}\end{array}$ & 0.264991 & 0.001053 & 0.0408 \\
\hline Exports & $\begin{array}{l}0.0009 \\
(9.01)^{* *}\end{array}$ & 0.001003 & 0.000000 & 0.0468 \\
\hline Instability & $\begin{array}{c}-0.0002 \\
(12.198)^{* *}\end{array}$ & -0.000214 & 0.000000 & 0.1437 \\
\hline High dependence & $\begin{array}{l}-146.1379 \\
(-1.801)^{*}\end{array}$ & -81.601444 & 1129.877477 & 0.0549 \\
\hline Medium dependence & $\begin{array}{c}-81.6014 \\
(-0.237)\end{array}$ & & & \\
\hline Low dependence & $\begin{array}{c}-1294.2710 \\
(-1.536)\end{array}$ & & & \\
\hline
\end{tabular}




\begin{tabular}{|l|c|c|c||}
\hline Hausman $\chi_{5}^{2}$ & 23.582 & [0.0003] & \\
\hline R-Squared & 0.8215 & & \\
\hline Adj. R-Squared. & 0.8174 & & \\
\hline S.E. or regression & 335.9628 & & \\
\hline F-statistic & 198.5704 & & \\
\hline & & & \\
\hline Sample & $1996-2005$ & & \\
\hline $\begin{array}{l}\text { Total panel } \\
\text { (balanced)observations }\end{array}$ & 310 & & \\
\hline Cross-sections & 31 & & \\
\hline
\end{tabular}

The results also show a negative relationship between high commodity dependence. Though the level of significance of the dependency coefficient was marginal (at 90 per cent level of significance) it is worth noting. On the other hand medium and low commodity dependence appeared to have no significant effect on output growth. It may be argued that the effect of commodity dependence may impact these economies through instability in earnings and not dependence per se.

The control variables represented by changes in export earnings, gross capital formation and the size of the labour force respectively, produced coefficient estimates that are consistent with the literature on neoclassical growth theory. The coefficients of exports, labour force and capital formation were positive. Historically, primary commodity export booms have been associated with increased economic growth while increases in gross capital formation tend to support increased economic growth.

\section{5}

\section{Conclusions and policy implications}

The paper sought to ascertain the effect of instability in primary commodity export earnings on economic growth in Sub Sahara Africa. The associated objective was to examine whether the level of commodity dependence matters in terms of economic growth. A balanced panel data set was used in fixed effects estimation. Instability in exports as well as high commodity dependence were negatively related to economic growth. The results suggest that the economic growth challenge that confronts SSA is probably not just the sheer presence of instability in earnings, an unavoidable phenomenon of business cycles, but that the level of commodity dependence also matters. Thus the issue of high level of dependence on a narrow range of primary commodities is a matter that has to be addressed.

The results of the paper have economic development policy implications for SSA economies and these are not far fetched. First, it appears the difficult growth experience of SSA is not solely due to instability in export receipts. The question of continued dependence on a narrow range of primary commodities is also a matter of great importance. For instance 34 out of the 48 SSA countries rely on three or less major primary commodities for the more than 50 per cent of their foreign exchange earnings. There is therefore an urgent need for diversification of the export base of these countries in the short to medium term. In the long term however, deliberate efforts need to be directed at diversifying exports to include manufactured products. Hitherto, conventional wisdom has pushed for market stabilisation among others. Even though these efforts are important there ought to be a rethinking to move out of gross commodity dependence especially for countries like Burkina Faso and Mali that depend almost entirely on cotton exports.

Development policies need to be aimed at export-led growth in the manufacturing and 
service sectors. Nonetheless, we do not suggest all countries on the continent can follow such a prescription. More so since some landlocked parts of Africa may not necessarily be successful in export-led growth in manufacturing in lowwage industries, because of high transport costs.

\section{Endnotes}

1 Thirty four (34) out of the 42 heavily indebted poor countries are in Africa

\section{List of references}

1 ADAMS, F.G.; BEHRMAN, J.R. \& ROLDAN, R.A. (1979) "Measuring the impact of primary commodity fluctuations on economic development: Coffee in Brazil". American Economic Review, 69(2).

2 AKIYAMA, T.; BAFFES, J.; LARSON, D.F. \& VARANGIS, P. (2003) "Commodity market reform in Africa: Some recent experience", World Bank Policy Research Working Paper, 2995, The World Bank: Washington D.C..

3 BADIENNE, O.; GHURA, D.; GOREUX, L. \& MASON, P. (2002) "Cotton sector strategies in West and Central Africa", World Bank Policy Research Working Paper 2867, The World Bank: Washington, D.C.

4 BAFFES, J. (2001) "Policy reform experiences in cotton markets", in: Akiyama, Baffes, Larson and Varangis (eds.) Commodity Market Reforms: Lessons of two Decades, The World Bank: Washington D.C..

5 FEDER, G. (1983) "On exports and growth", Journal of Development Economics, 12: 59-73.

6 GLEZAKOS, C. (1984) "Export instability and economic growth: Reply", Economic Development and Cultural Change, 32: 229-36.

7 GREEN, W. (1997) Econometric Analysis (3 ${ }^{\text {rd }}$ ed.) Prentice-Hall: NJ.

8 GREEN, D.P.; KIM, S.Y. \& YOON, D.H. (2001) "Dirty pool", International Organization, 55(2): 441-468.

9 GYIMAH-BREMPONG, K. (1991) "Export instability and economic growth in Sub-Saharan Africa", Economic Development and Cultural Change, 39: 815-28

10 HAUSMAN, J. (1978) "Specification tests in econometrics", Econometrica, 46: 1251-1271.

11 IMF (2006) International Financial Statistics, CD Rom. The International Monetary Fund: Washington, D.C.
12 JURAJDA, S. \& MITCHELL, J. (2001) Markets and Growth, Cerge-Ei and ECARES, CEPR, WDI. Charles University, Prague. September.

13 KENEN, P.B. \& VOIVODAS, C. (1972) "Export instability and economic growth", Kyklos, 25: 791801.

14 KNUDSEN, O. \& PARNES, A. (1975) Trade Instability and Economic Development, Heath: London.

15 KRUGER, A.O.; SCHIFF, M. \& VALDES, A. (eds.) (1991) The Political Economy of Agricultural Pricing Policy, John Hopkins University Press: Baltimore.

16 LAM, V.M. (1980) "Export instability and primary commodity concentration", Economia Internazionale, 33, 1:40-57.

17 LARSON, D.; VARANGIS, P. \& YABUKI, N. (1998) "Commodity risk management and development”, World Bank Policy Research Working Paper 1963, The World Bank: Washington, D.C.

18 LOVE, C. (1992) "Export instability and the domestic economy: Questions of causality", Journal of Development Studies, 28: 735-42.

19 MACBEAN, A.I. (1966) Export Instability and Economic Development, Allen \& Unwin: London.

20 MAIZELS, A. (1968) "Review of export instability and economic development by Macbean", American Economic Review, 58: 575-580.

21 MULlOR-SEBASTIAN, A. (1988) "Export fluctuations and economic growth", Economic Development and Cultural Change, 36(3): 217-36.

22 MUNDLAK, Y.; CAVALLO, D. \& DOMENCH, R. (1993) "Agriculture and economic growth in Argentina, 1913-84", Research Report No. 76, International Food Policy Research Institute: Washington, D.C..

23 OBIDEGEWU, C.F \& NZIMASANGA, M. (1981) Copper and Zambia: An Econometric Analysis, Heath: Lexington, Mass.

24 OCRAN, M.K. (2005) "Trade barriers in Sub-Saharan Africa and their implications for intra-Africa trade", in Nicholas Biekpe and Fikele Rouguet (eds.) Export Growth Opportunities in Africa, Africa Growth Research/African Centre for Investment Analysis/University of Stellenbosch.

25 OZLER, S \& HARRIGAN, J. (1988) “Export instability and growth", Department of EconomicsWorking Paper, No. 486, University of California, Los Angeles.

26 PRIOVOLOS, T. (1981) Coffee and the Ivory Coast: An Econometric Study, Heath: Lexington, Mass.

27 SAVVIDES, A. (1984) "Export instability and economic growth: Some evidence", Economic Development and Cultural Change, 32: 607-14. 
28 SINHA, D. (1999) "Export instability, investment and economic growth in Asian countries: A time series analysis", Economic Growth Centre Discussion, Paper, No. 799, April, Yale University and Macquarie University, Australia.

29 YOTOPOULUS, P.A \& NUGENT, J.B. (1977) Economic Development: Empirical Investigations, Harper \& Row: New York.

30 UNCTAD (2004) Economic Development in Africa: Trade Performance and Commodity Dependence, United Nations Conference on Trade and Development: Geneva.
31 VARANGIS, P. \& SCHREIBER, G. (2000) "Cocoa market reforms in West Africa: Policy challenges”, World Bank Technical Paper No. 444. The World Bank: Washington, D.C.

32 WILSON, P. (1994) "Export earnings and instability in Singapore, 1957-1988: A Time Series Analysis", Journal of Asian Economics 5: 399-412.

33 WORLD BANK (2007) World Development Indicators, The World Bank: Washington, D.C. 